\title{
A Preliminary Scanning Electron Microscope Examination of Wear Striation Direction on Primate Teeth
}

\author{
ALAN S. RYAN
}

Department of Anthropology, The University of Michigan, Ann Arbor, Michigan 48109

Wear striations experimentally produced on initially unworn teeth were examined at high magnification using a scanning electron microscope. Certain characteristics of individual wear striations on these teeth indicate the direction of motion that produced them. Other striations on worn teeth of American Indians and the Paleocene primate Phenocolemur show similar characteristics and correspond to mandibular movement during mastication.

J Dent Res 58(1):525-530, January 1979

Introduction.

The interpretation of striated wear facets on the teeth of fossil and living mammals has provided valuable information on mastication in mammals. ${ }^{1-14}$ Much of the chewing behavior of an animal can be reconstructed by analyzing the orientation of the striations on these wear facets. It has been suggested by Butler, ${ }^{1}$ Butler and Mills, ${ }^{4}$ Mills $^{2-3}$ and others that two distinct sets of striations exist, indicating two separate directions or phases of mandibular movement during mastication. These two sets correspond to the buccal and lingual phases of mastication, involving first an upward, forward and medial and then a downward, forward and medial mandibular movement, in sequence. Such studies, coupled with cineradiographic investigations of chewing in living animals, have described in detail the relationship between the direction of masticatory movement and buccal and lingual phase striated molar wear facets. ${ }^{10,11,15,16}$

While the orientation of wear striations has been examined, a detailed description of the characteristics of individual wear striations that correspond to the direction of documented jaw movements has not been performed. This study will document and describe those characteristics of individual

Received for publication August 3, 1977.

Accepted for publication March 2, 1978.

This investigation was supported, in part, by the Museum of Anthropology, The University of Michigan. wear striations that indicate the direction of certain jaw movements.

The logical approach of this study is to experimentally produce wear striations on unworn teeth in one direction, note those characteristics that are indicative of the direction of wear, and then compare these striations to those that have been produced in living animals during mastication. The capability of examining individual wear striations can be achieved by using the scanning electron microscope (SEM).

\section{Materials and methods.}

The sample studied consisted of two groups: twenty-five American Indian newlyerupted incisors which served as an experimental control, and twenty-one Phenacolemur (a late Paleocene primate) and twentytwo American Indian worn dentitions which had wear striations produced during mastication.

The control group was examined under a binocular microscope, and those teeth that were not worn and did not exhibit preservation damage were selected as a test sample $(n=22)$. The occlusal surface of each of the incisors was then drawn, by hand, in one direction (with the buccal surface as the leading edge), across a flat glass surface covered with fine loose sand. The direction the tooth was drawn across the gritty, glass surface is indicated by a large arrow in Figures 1 B, C, D and E. Constant, even pressure was applied to the tooth as it was drawn across this surface. This method to produce wear striations was repeated several times for each specimen. This experiment was not designed to simulate jaw movement but rather to recreate the conditions involved in the production of wear striations of known direction on enamel when abrasive material is sandwiched between two hard surfaces as they slide across each other. 
Both the control group and the sample of worn teeth were carefully cleaned with acetone in order to eliminate contamination by dust particles. A rubber-based dental molding compound* was immediately prepared, spread over the crowns of the teeth, allowed to dry and removed. This mold was then filled with an epoxy casting solution $\dagger$ and allowed to dry. The casts were

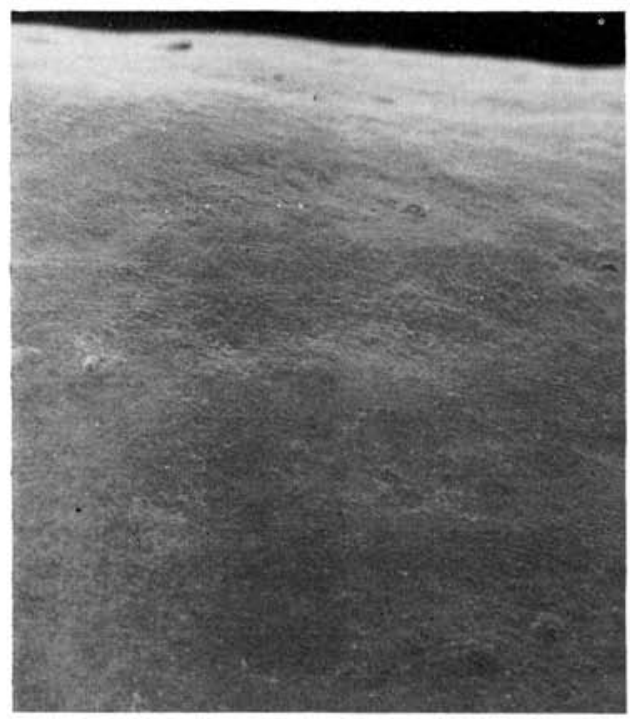

Fig. 1 A. - Scanning electron micrograph of the surface of an unworn newly-erupted incisor before the experiment to produce wear striations was performed (magnification approximately $\times 150$ ). Note the lack of any scratches, grooves or pits.

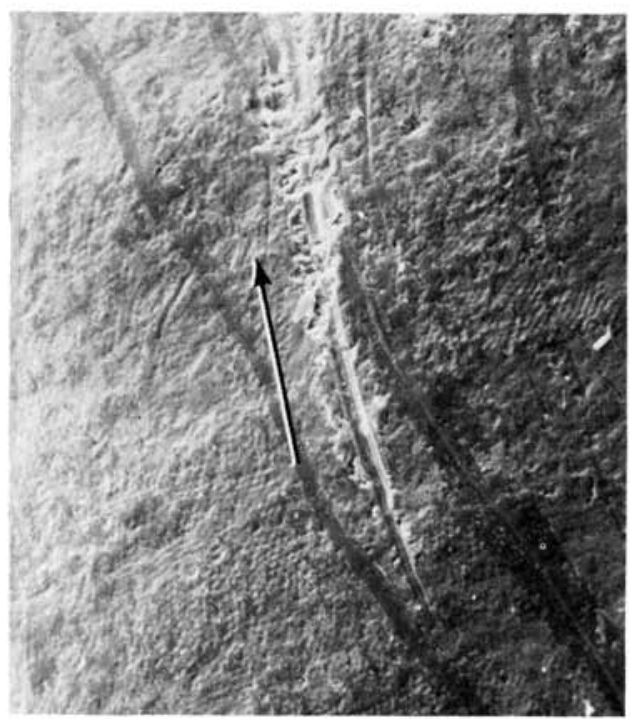

Fig. $1 \mathrm{~B}$.

Fig. $1 \mathrm{C}$.
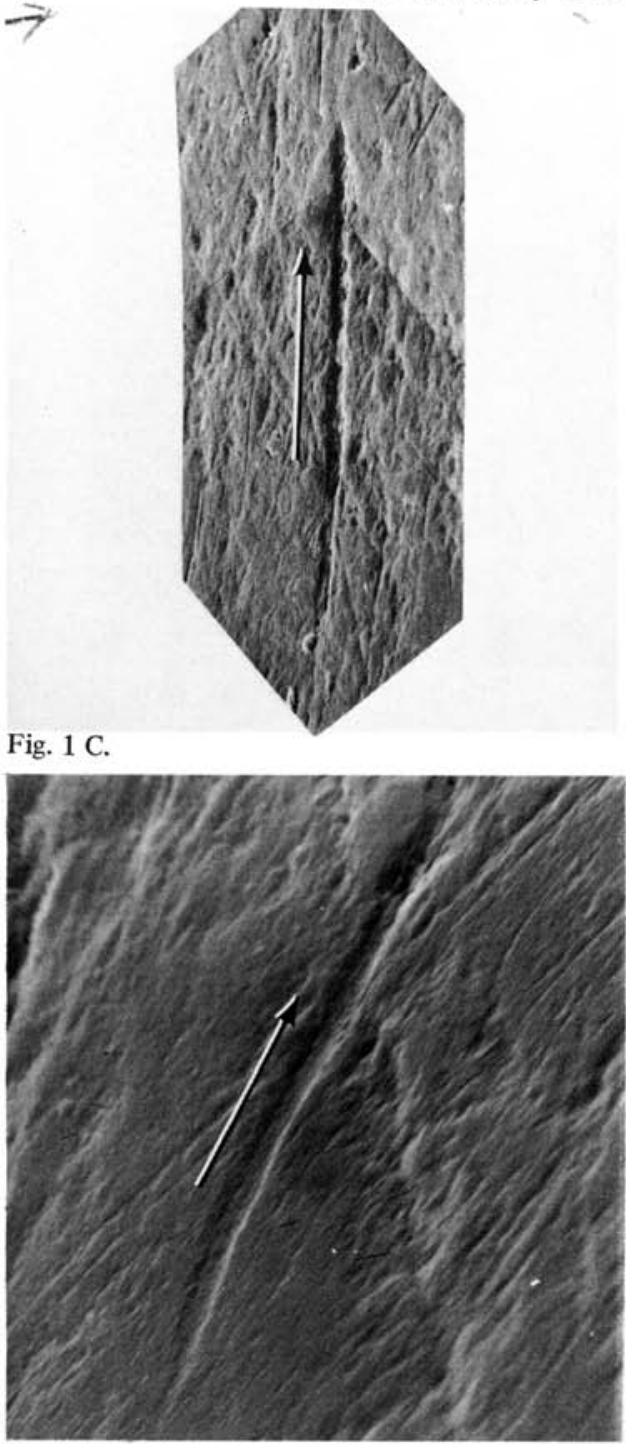

Fig. 1 D.

Figs. 1 B, C, D. - Scanning electron micrographs of the surfaces of the teeth after the experiment was performed (magnification approximately $\times 175, \times 2000$ and $\times 6000$, respectively). Large arrows indicate the direction these teeth were drawn across the gritty glass surface. Note that at the point of initial contact, i.e., when the tooth comes into contact with the particle of grit (upper half of micrographs), these striations are broadly pitted with extending grooves that become narrower (lower half of micrographs)-characteristics that indicate the direction of wear.

*Silastic A RTV \#3110, Tool Chemical Company, Ferndale, MI. MI.

$\dagger \# 130$, Michigan Fiberglass Sales, East Detroit, 
then removed from the molds and mounted on SEM stubs.

A vacuum unit especially designed to prevent damaging heat sensitive material was used to vapor coat the casts with gold. The casts were examined at low power (X100) for orientation and at high magnification (X600, X1000, X5000, X10,000) to examine individual wear striations. Micrographs were taken of those specimens showing distinct and clearly striated teeth.

\section{Results and discussion.}

Patterns of individual wear striations on the worn teeth of American Indians and Phenacolemur were found to be similar to those produced on the artificially-worn control group. Figure 1 A illustrates the surface of a newly-erupted incisor before the striations were experimentally produced. Note the lack of any striations, pits or preservation damage on the tooth surface. Figures $1 \mathrm{~B}, \mathrm{C}$ and D illustrate the striations on the control specimens after the experiment was performed. These show certain

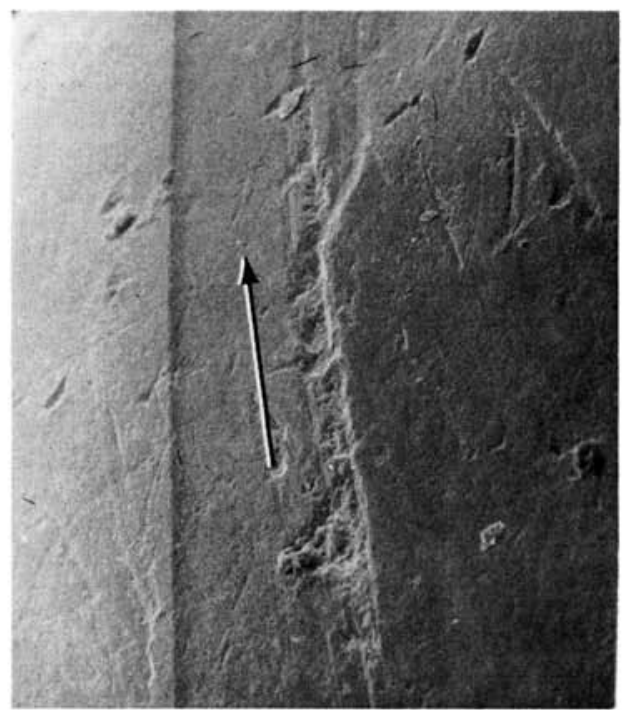

Fig. 1 E. - Scanning electron micrograph to illustrate a pattern of wear striation produced experimentally that does not indicate direction (magnification approximately $\times 200$ ). Large arrow indicates the direction this tooth was drawn across the gritty glass surface. Note that at the point of initial contact (upper half of micrograph), the characteristic broad pit and extending groove that becomes narrower (lower half of micrograph) should be present but does not appear. characteristics that correspond to the direction the tooth was drawn across the gritty glass surface. At the point of contact, there is a pit produced by a particle of sand sandwiched between the enamel and glass surfaces. As the particle of sand is drawn across the tooth surface, an extending broad groove which gradually becomes narrower is produced. Not all individual wear striations clearly show this pattern (Fig. 1 E). However, it is important to note that no wear striations on the control group specimens show a reverse pattern, i.e., striations that begin with a narrow groove that gradually become broadly grooved and end with a pit. Therefore, it appears that some wear striations can be used to determine the direction of wear.

Figure $2 \mathrm{~A}$ illustrates an American Indian upper left maxillary second premolar at low magnification (see Figs. $3 \mathrm{~A}$ and $\mathrm{B}$ for orientation). The striations on this tooth begin near the border of the lingual cusp and extend toward the base of the crown. At high magnification of the same specimen, the SEM micrographs of individual wear striations exhibit characteristics similar to those observed on the experimental control specimens (compare Figs. $1 \mathrm{~B}, \mathrm{C}$ and D to

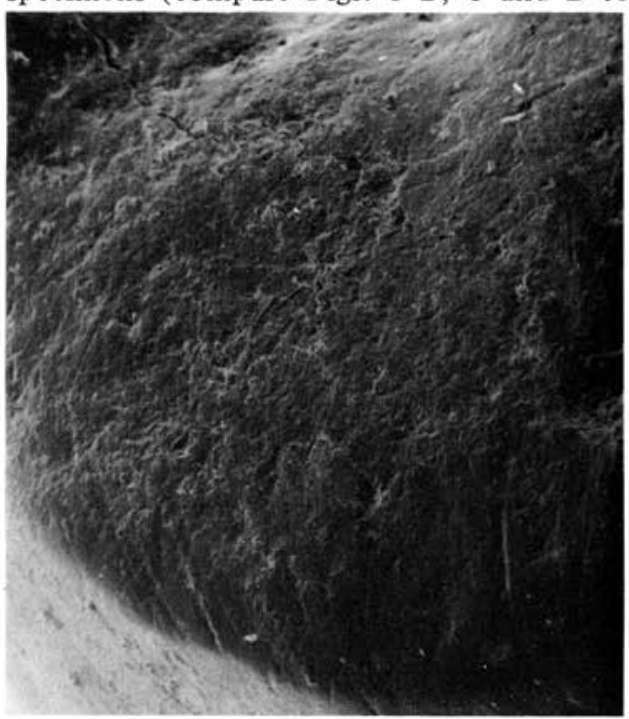

Fig. 2 A. - Scanning electron micrograph of the lingual cusp of a maxillary left second premolar of an American Indian to illustrate the location of the wear striations (magnification approximately $\times 40$; compare with Fig 3 B for orientation). The striations appear to originate near the border of the lingual cusp and extend toward the base of the crown. 
Figs. 2 B, C and D). These striations appear to correspond to a well-documented movement of the jaw, ${ }^{2-4}$ i.e., the buccal phase of mastication when the mandible is drawn upward, forward and slightly medial (Fig. 3 A).

Individual wear striations on other worn teeth of American Indians and on the cheek teeth of Phenacolemur (Fig. 2 E) show similar characteristics discussed here and apparently also correspond to movements of the jaw. Variation in pit size, groove width and groove length may be related to the size and shape of the particle of grit as well as the force on the occlusal surfaces as the striation is created during mastication. For example, the depth and angularity of the pit and groove in Fig. $2 \mathrm{C}$ may indicate that this particular striation was produced by a smaller, more angular sand particle resulting in a slice-like appearance. The ability to document variation in pit and groove size may provide valuable information on the consistency and kind of grit being introduced into the diet. However, additional experimental and comparative studies are needed to determine the relationship between variation in striation pit and groove morphology and dietary factors. In sum, although pit size, groove width and groove length vary, the direction of wear is clearly demonstrated by a characteristic wear striation form.

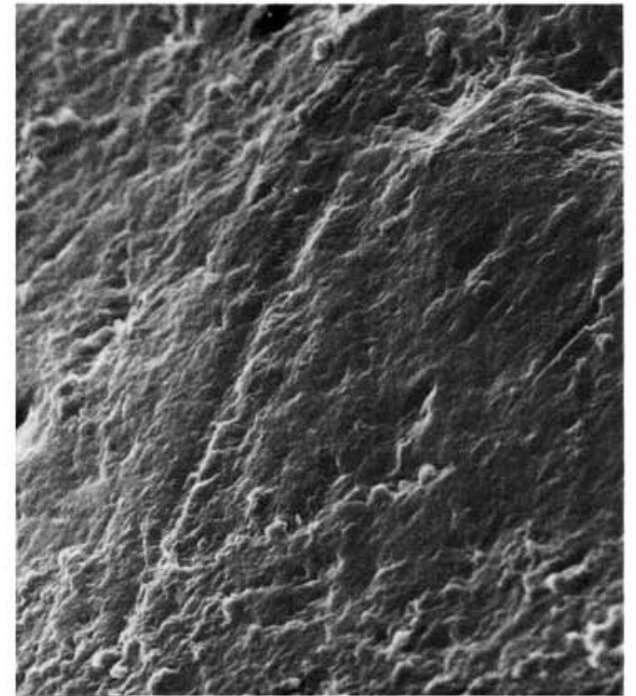

Fig. 2 B.

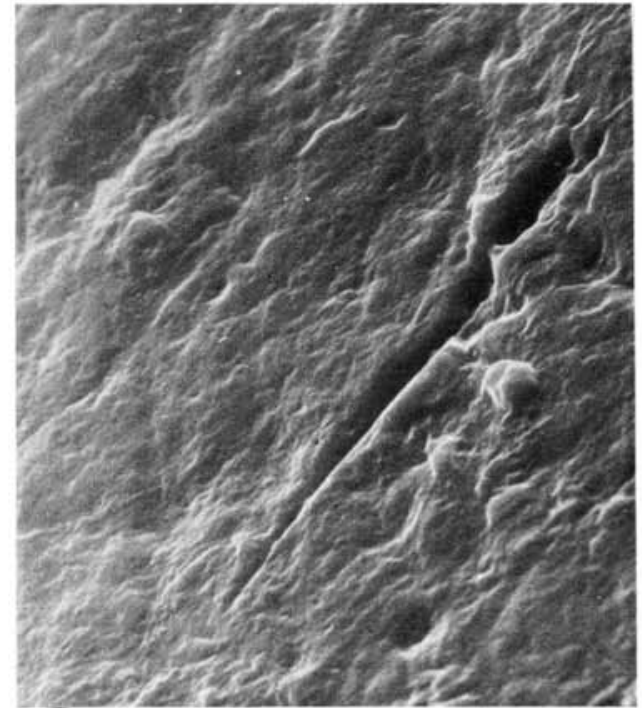

Fig. 2 C.

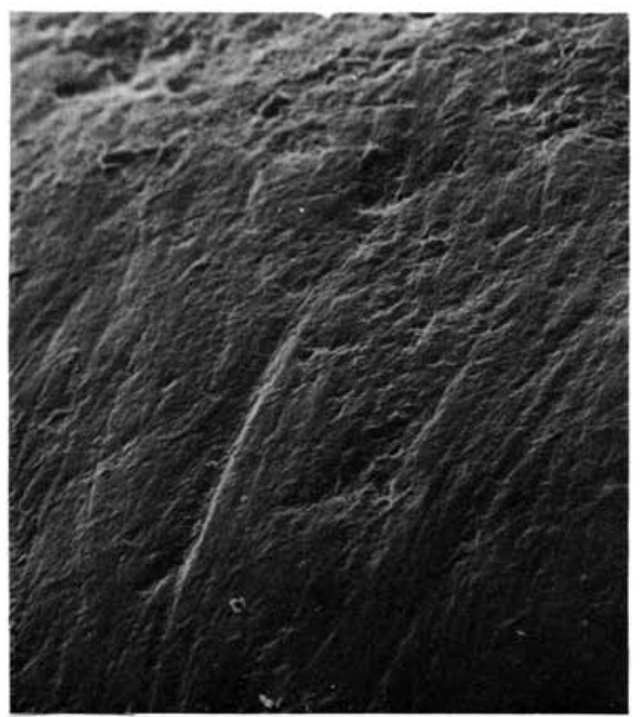

Fig. 2 D.

Figs. 2 B, C, D. - Scanning electron micrographs taken of individual wear striations in the same area illustrated in $2 \mathrm{~A}$ (magnification approximately $X 450, \times 1250, \times 1800$, respectively). Note in all examples the characteristic broadly pitted point of contact with an extending groove that becomes narrower and which seems to correspond to the buccal phase of mastication when the mandible is drawn upward, forward and slightly medial (compare with Figs $1 \mathrm{~B}, \mathrm{C}$ and D). Variation in pit size and groove width and length may be related to particle morphology as well as the masticatory force (see text). 


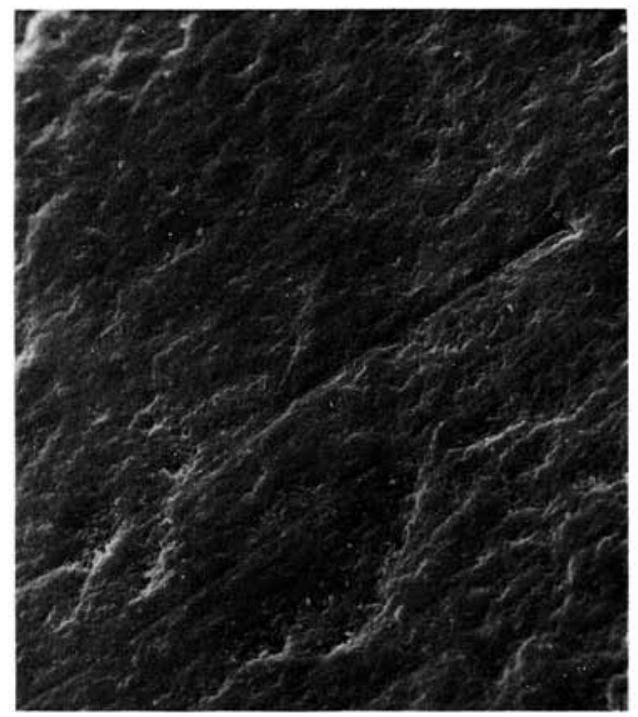

Fig. 2 E. - Scanning electron micrograph to illustrate a buccal phase wear striation located on the hypoconid of the mandibular left first molar of Phenacolemur (magnification approximately $\times 600$ ). The striations on the cheek teeth of Phenacolemur also exhibit characteristics that correspond to the direction of mandibular movements during mastication.

\section{Conclusion.}

This preliminary investigation presents evidence that it is possible to determine the direction of mandibular movement from a detailed analysis of individual wear striations on the teeth of primates. The determination of the direction of jaw movements producing such striations further substantiates studies on the reconstruction of chewing behavior of fossil and living animals. When jaw movements are determined in many other animals, a more useful functional interpretation of jaw mechanics can be made.

\section{Acknowledgments.}

The dental materials used in this study were made available by the Museum of Anthropology and the Museum of Paleontology, The University of Michigan. The author thanks Drs. C. Loring Brace, Philip D. Gingerich, Milford $\mathrm{H}$. Wolpoff and Mr. Wm. $\mathrm{K}$. Macdonald for comments and discussion relating to this paper.

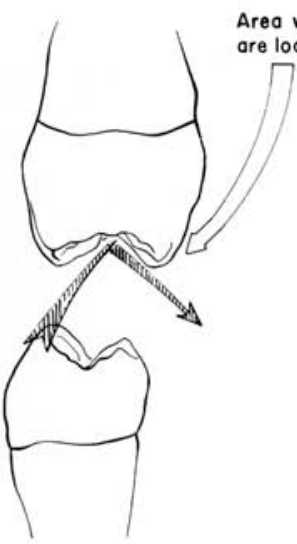

A
Area where Buccal Phase Striations are located.

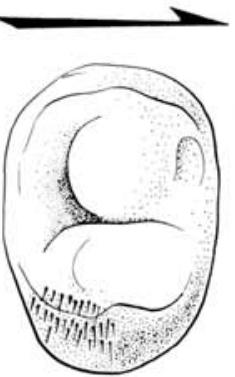

B
Fig. 3 A. - Distal aspect of American Indian maxillary and mandibular second left premolars to schematically illustrate movement of the jaw during mastication. In the buccal phase, the lower premolar is moving upward, forward and slightly medially into centric occlusion (left part of arrow), and in the lingual phase, downward, forward and medially out of centric occlusion (right part of arrow). Large white arrow indicates area where scanning electron micrographs were taken to illustrate the buccal phase striations possibly produced by tooth-tooth contact during the buccal phase of mastication.

Fig. 3 B. - Occlusal aspect of the maxillary left second premolar to illustrate the location of buccal phase wear striations. Large black arrow is buccal to tooth and points distally. This orientation was used to take the scanning electron micrographs.

\section{REFERENCES}

1. BUTLER, P. M.: The Milk-Molars of Perrissodactyla, with Remarks on Molar Occlusion, Proc Zool Soc Lond 121:778-817, 1952.

2. MILLS, J. R. E.: Occlusion and Malocclusion of the Teeth of Primates, in: Dental Anthropology, BROTHWELL, D. R. (ed): Oxford: Pergamon Press, 1963, pp 29-52.

3. MILLS, J. R. E.: A Comparison of Lateral Jaw Movements in Some Mammals from Wear Facets on the Teeth, Arch Oral Biol 12:645$661,1967$.

4. BUTLER, P. M.: and MILLS, J. R. E.: A Contribution to the Odontology of Oreopithecus, Bull Brit Mus Nat Hist (Geology) 4:3-26, 1959.

5. CROMPTON, A. W.; and JENKINS, F. A.: Molar Occlusion in Late Triassic Mammals, Biol Reviews 43:427-458, 1968.

6. CROMPTON, A. W.: The Origin of the Tribospheric Molar, in: Early Mammals, KERMACK, 
D. M., and KERMACK, K. A. (eds): Zool $J$ Lin Soc 50: Supp1 1:65-87, 1971.

7. GINGERICH, P. D.: Molar Occlusion and Jaw Mechanics of the Eocene Primate Adapis, Am $J$ Phys Anthrop 36:359-368, 1972.

8. GINGERICH, P. D.: Molar Occlusion and Function in the Jurassic Mammal Docodon, $J$ Mammal 54:1008-1013, 1973.

9. GINGERICH, P. D.: Cranial Anatomy and Evolution of Early Tertiary Plesiadapidae (Mammalia, Primates), Univ Michigan Pap Paleont 15:1-140, 1976.

10. HIIEMAE, K. M.; and KAY, R. F.: Evolutionary Trends in the Dynamics of Primate Mastication, in: Symp Fourth Int Cong Primatology, 3: Karger: Basel, 1973, pp 28-64.

11. KAY, R. F.; and HIIEMAE, K. M.: Jaw Movement and Tooth Use in Recent Fossil Primates, Am J Phys Anthrop 40:227-256, 1974.
12. KAY, R. F.: The Functional Adaptations of Primate Molar Teeth, Am J Phys Anthrop 43: 195-216, 1975.

13. KAY, R. F.: The Evolution of Molar Occlusion in the Cercopithecidae and Early Catarrhines, Am J Phys Anthrop 46:327-352, 1977.

14. ROSE, K. D.: The Carpolestidae: Early Tertiary Primates from North America, Bull Mus Comp Zool 147:1-74, 1975.

15. CROMPTON, A. W; and HIIEMAE, K. M.: Functional Occlusion and Mandibular Movements During Occlusion in the American Opossum, Didelphis marsupialis, $L$ Zool $J$ Lin Soc 49:21-47, 1971.

16. KAY, R. F.; and HIIEMAE, K. M.: Mastication in Galago crassicaudatus, A Cinefluorographic and Occlusal Study, in Prosimian Biology, MARTIN, R. D., DOYLE, G. A., and WALKER, A. C. (eds): London: Duckworth, 1974, pp 501-530.

\section{ENDODONTICS CAREER OPPORTUNITY EXCHANGE}

The annual meeting of the American Association of Endodontists is the ideal time and place at which information on career opportunities in Endodontics can be made readily available to those both seeking or offering such opportunities.

Although the precise mechanics have not yet been established, a convenient space will be provided during the meeting where interested parties can examine and exchange such material and perhaps receive guidance.

The effectiveness of this new undertaking will be determined to a large extent by the amount and types of information submitted. We therefore urge all endodontic students, practitioners, teachers and administrators who are interested in either finding or filling a position in Endodontics to contact us immediately so that the material can be collected and organized in preparation for the April 1979 meeting.

The committee is making up a questionnaire which will be sent to those who wish to take advantage of this exchange, but we suggest that at this time you send us pertinent information and vital statistics regarding the type of position being sought or of fered.

Strict confidentiality will be observed when requested.

Communicate with: Dr. Joseph M. Leavitt

Columbia U., Sch. D\&OS

630 West 168 th Street

New York, N.Y. 10032 